\title{
Plutonium Immobilization Form Development Interim and Final Data Report Summaries
}

\author{
R. VanKonynenburg and B. Ebbinghaus \\ June 1, 2000
}

U.S. Department of Energy

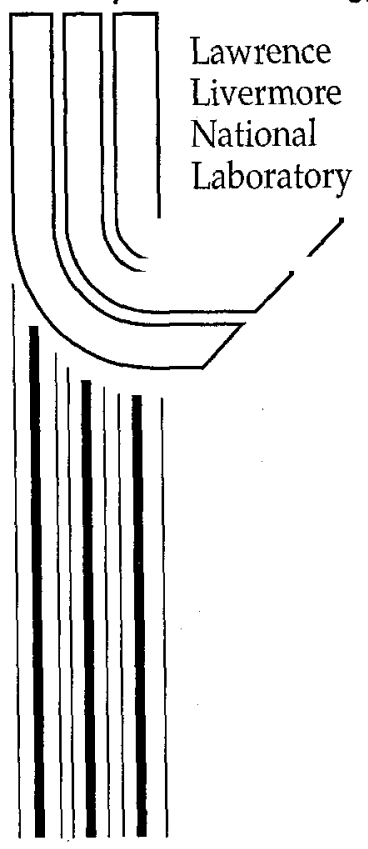




\section{DISCLAIMER}

This document was prepared as an account of work sponsored by an agency of the United States Government. Neither the United States Government nor the University of California nor any of their employees, makes any warranty, express or implied, or assumes any legal liability or responsibility for the accuracy, completeness, or usefulness of any information, apparatus, product, or process disclosed, or represents that its use would not infringe privately owned rights. Reference herein to any specific commercial product, process, or service by trade name, trademark, manufacturer, or otherwise, does not necessarily constitute or imply its endorsement, recommendation, or favoring by the United States Government or the University of California. The views and opinions of authors expressed herein do not necessarily state or reflect those of the United States Government or the University of California, and shall not be used for advertising or product endorsement purposes.

Work performed under the auspices of the U. S. Department of Energy by the University of California Lawrence Livermore National Laboratory under Contract W-7405-Eng-48.

This report has been reproduced directly from the best available copy.

Available to DOE and DOE contractors from the Office of Scientific and Technical Information

P.O. Box 62, Oak Ridge, TN 37831

Prices available from (423) 576-8401

http:/ / apollo.osti.gov/bridge/

Available to the public from the National Technical Information Service

U.S. Department of Commerce 5285 Port Royal Rd., Springfield, VA 22161 http://www.ntis.gov/

OR

Lawrence Livermore National Laboratory Technical Information Department's Digital Library http://www.llnl.gov/tid/Library.html 
Fissile Materials Disposition Program

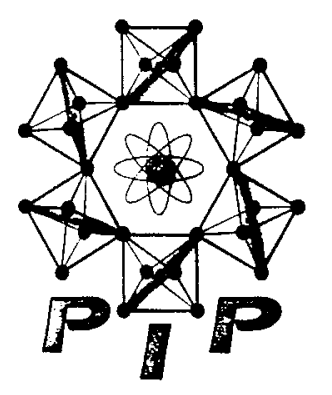

Plutonium Immobilization Project Plutonium Immobilization Form Development Interim and Final Data Report Summaries

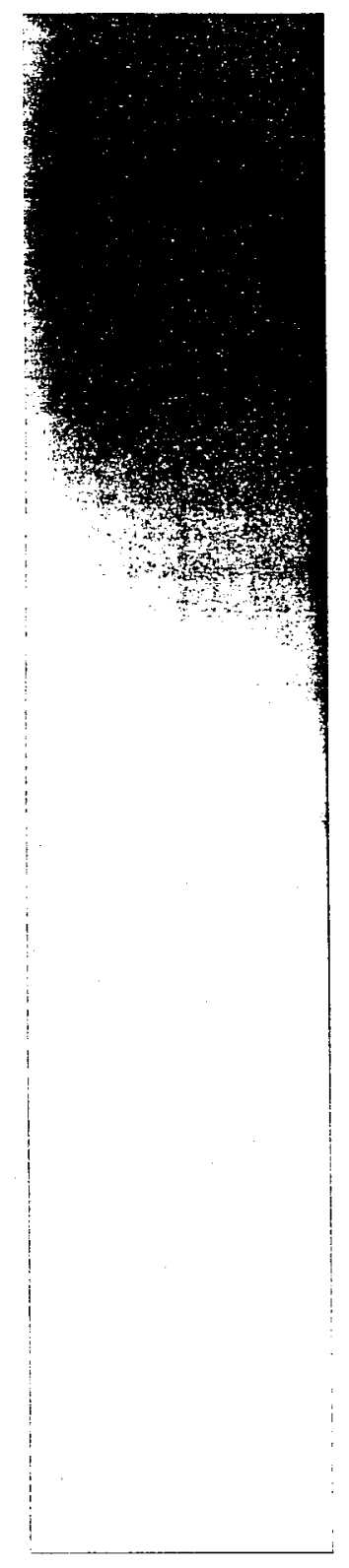

June 2000

Rich VanKonynenburg

Bartley Ebbinghaus

Plutonium Immobilization Project

Lawrence Livermore National Laboratory

Livermore, California 94550 


\title{
Plutonium Immobilization Form Development Interim and Final Data Report Summaries
}

\author{
Rich VanKonynenburg, LLNL \\ Bartley Ebbinghaus, LLNL
}

Milestone FY99-3.4a

June 2000

This document was reviewed in accordance with LLNL D\&T QA Implementing Procedure LQIP-6.2 Rev 0.0 - Document Review. The data included or referenced in this report may not have been collected in accordance with an approved $Q A$ program. Therefore, the contents and reference data are considered unqualified. 


\section{PIP Approval Sheet}

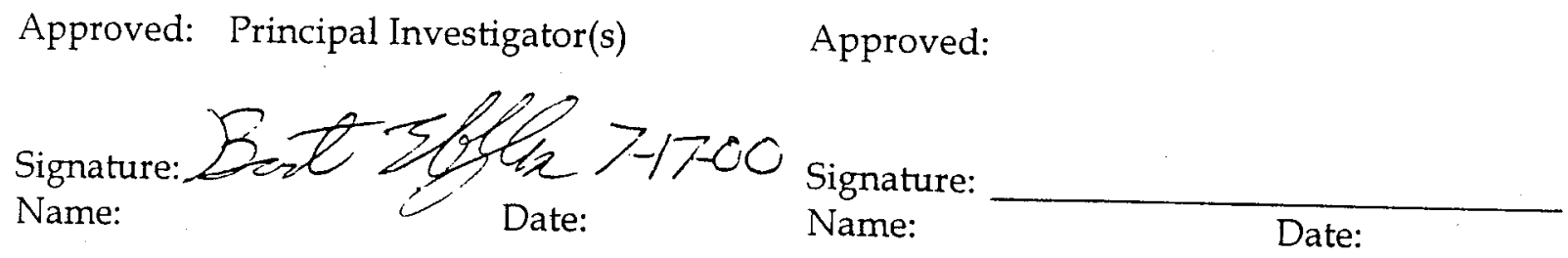

Approved: Site Leader

Signature:

Name:
Date:
Approved: Task Leader

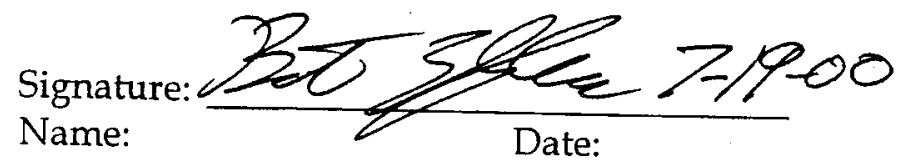

Approve: Activity Leader 


\section{Introduction}

Contained within this report are summaries of the available interim and final data summary reports provided by ANSTO, ANL, LLNL, and WSRC in support of work in the Form Development activity in the Plutonium Immobilization Development and Testing Program. Milestone reports and technical papers prepared for journals or conference proceedings are not included in this list. This document covers work from about 1997 to the present. All of the following reports are available from the Plutonium Immobilization Program Document Control Center (DCC) at LLNL. In most cases, the documents can also be obtained from the libraries at the originating site or from the document's authors.

All samples of the various formulations discussed in the following summaries were prepared by one of four processes: Wet-milling, dry-milling, an alkoxide-nitrate process, or attritor milling. The fabrication processes differ primarily in the mixing steps. The wet milling process is the one most commonly used. It is a simple ball milling process where water is added that provides intimate mixing of the materials. The dry milling process is a worst case dry mixing process. The alkoxide-nitrate process provides for very intimate mixing and is used when equilibrium samples are desired. The attritor milling process simulates the process being developed for the Plutonium Immobilization Plant. After mixing, the subsequent calcination and consolidation steps are generally the same. Most samples were consolidated by cold pressing and sintering although some of the earlier samples or some of the single-phase samples were prepared by hot pressing.

The sample identification numbers (ID's) that are referenced in the summaries (e.g. A-0, B3-13, etc.) are described in the Sample Test Matrix (PIP-99-012 and PIP-00-016). Samples which contain both plutonium and uranium are given the designation $\mathrm{Hf}-\mathrm{Pu}-\mathrm{U}$ samples. When $\mathrm{Ce}$ was used as a surrogate for $\mathrm{Pu}$, the designation is $\mathrm{Hf}-\mathrm{Ce}-\mathrm{U}$. When Th was used as a surrogate for $\mathrm{Pu}$, the designation is $\mathrm{Hf}-\mathrm{Th}-\mathrm{U}$. When $\mathrm{Ce}$ was used as a surrogate for $\mathrm{Pu}$ and $\mathrm{U}$, the designation is $\mathrm{Hf}-\mathrm{Ce}-\mathrm{Ce}$. Lastly, when $\mathrm{Zr}$ was used as a surrogate for $\mathrm{Hf}$ and $\mathrm{Ce}$ was used as a surrogate for $\mathrm{Pu}$ and $\mathrm{U}$, the designation is $\mathrm{Zr}-\mathrm{Ce}-\mathrm{Ce}$.

\section{Summary and Conclusion}

From the vast amount of data that has been collected and compiled, it has been shown that the ceramic form is relatively easy to make, it forms durable phases, and is tolerant to a wide variety of process impurities. Cold pressing and sintering can be used for fabrication. Hot isostatic pressing or hot uniaxial pressing is not required. Good densification and reaction is obtained if good mixing is obtained. The baseline phases are pyrochlore, brannerite, zirconolite, and rutile and these are not significantly modified when different fabrication processes are used. The zirconolite phase is generally the zirconolite- $2 \mathrm{M}$ form although in some circumstances it may be zirconolite-4M.

The phase equilibria are well understood. There are six components in the baseline system, $\mathrm{CaO}$, $\mathrm{Gd}_{2} \mathrm{O}_{3}, \mathrm{UO}_{2}, \mathrm{PuO}_{2}, \mathrm{HfO}_{2}$, and $\mathrm{TiO}_{2}$. Phase equilibria in all sub-systems involving these components have been studied and documented. In many experiments, cerium and thorium have been used as surrogates of plutonium. Although there are some differences, the chemical 
behavior of cerium, thorium, and plutonium are sufficiently similar that the wide range of testing with surrogates has been validated.

A number of tests have been performed with impurities. In most cases, very large quantities of impurities are required in order to make any detrimental effect on the form. Based on these tests, it appears that the impurities present in the plutonium feed streams will not present any problems in the ceramic form.

As a result, small scale testing of the ceramic form is generally complete and the form is ready for full scale testing in plant protypical equipment. The are no show stoppers for the pyrochlorebased plutonium ceramic form. 


\section{ANSTO Reports}

Reports provided by ANSTO are summarized in this section. Twelve interim and final data summary reports have been prepared by ANSTO in support of the Form Development activity. The first report ( $\mathrm{R} 97 \mathrm{~m} 030$ ) was provided under contract B336960. All other reports were provided under contract B345772.

The titles of the ANSTO reports are as follows:

- Pyrochlore-Rich Titanate Ceramics for Incorporation of Plutonium, Uranium and Process Chemicals

- Interim Report on Task 1.1: Single-Phase Sample Production

- Report on Phase 2 of Task 1.1: Single Phase Synthesis

- Interim Report on Task 1.2: Near Equilibrium Processing Requirements

- Interim Report on Task 1.2: Near Equilibrium Processing Requirements- Attrition Milling

- Interim Report on Task 1.3: Equilibrium Phase Diagram

- Supplement to Interim Report on Task 1.3: Equilibrium Phase Diagram

- Update of Interim Report on Task 1.3: Equilibrium Phase Diagram

- Interim Report on Task 1.3: Equilibrium Phase Diagram

- Interim Report on Task 1.3: Equilibrium Phase Diagram

- Task 1.3: Equilibrium Phase Diagram Phase 3(ii): Phase Equilibria in the $\mathrm{TiO}_{2}$-rich portion of the $\mathrm{CaO}-\mathrm{AnO}_{2}-\mathrm{TiO}_{2}$ Ternary $(\mathrm{An}=\mathrm{Ce}, \mathrm{Th}, \mathrm{U}$, or $\mathrm{Pu})$

- Interim Report on Task 1.4: Impurity Effects 
E.R. Vance, M.W.A. Stewart, R.A. Day, K.P. Hart, M.J. Hambley, and A. Brownscombe, "Pyrochlore-Rich Titanate Ceramics for Incorporation of Plutonium, Uranium and Process Chemicals," 180 pp, R97m030, November 1997 (000258).

This report discusses work directed toward the following objectives:

1. To delineate the zirconolite/pyrochlore phase boundary in the $\mathrm{ABTi}_{2} \mathrm{O}_{7}$ system (where $\mathrm{A}=\mathrm{Ca}$, rare earth, actinide; $\mathrm{B}=\mathrm{Zr}$, rare earth, actinide), and to verify that the pyrochlore phase in a selected ceramic resides well within the pyrochlore region of stability.

2. To demonstrate the preparation and viability of oxide-process ceramics containing 95 wt. $\%$ pyrochlore, in which $10 \mathrm{wt} . \%$ of $\mathrm{Pu}, 20 \mathrm{wt} . \%$ of $\mathrm{U}$ and $14 \mathrm{wt} . \%$ of neutron absorbers were incorporated in the pyrochlore phase. The remaining $5 \mathrm{wt}$. \% was composed of Hf-bearing rutile.

3. To demonstrate that the above-mentioned ceramic phase assemblage was not unduly affected by the presence of small amounts of impurities.

4. To show that adverse effects will not result when the ceramic comes into contact with molten DWPF glass.

This work first demonstrated that the combination of $\mathrm{U}$ and $\mathrm{Pu}$ substituted on the $\mathrm{B}$ site of $\mathrm{ABTi}_{2} \mathrm{O}_{7}$-type pyrochlore must exceed about 0.6 formula units to stabilize pyrochlore. At smaller $\mathrm{U}$ and $\mathrm{Pu}$ contents, zirconolite rather than pyrochlore is formed, notwithstanding the presence of 0.11 formula units each of $\mathrm{Gd}$ and Sm, nominally partitioned equally between the A and B sites. To facilitate the approach to phase equilibrium, these samples were made using alkoxide and nitrate starting materials, followed by calcination, ball milling, and sintering for 4 hours at $1350^{\circ}$ $\mathrm{C}$ in an argon atmosphere. Although minor amounts of fluorite-structured $\left(\mathrm{Pu}, \mathrm{U} \mathrm{O}_{2+\mathrm{x}}\right.$ and brannerite-structured $(\mathrm{Pu}, \mathrm{U}) \mathrm{Ti}_{2} \mathrm{O}_{6}$ phases were observed, and their presence was attributed to still-imperfect solid-state reaction, the basic results gave a firm experimental basis to the LLNL strategy of using $\mathrm{Pu}$ and $U$ contents of 0.22 and 0.44 formula units, respectively, in the B site.

The LLNL-formulated titanate ceramics designed at $95 \mathrm{wt} . \%$ pyrochlore $\left(\mathrm{Ca}_{0.89} \mathrm{Gd}_{0.22} \mathrm{Pu}_{0.22} \mathrm{U}_{0.44} \mathrm{Hf}_{0.23} \mathrm{Ti}_{2} \mathrm{O}_{7}\right)$ and $5 \mathrm{wt}$. \% titania $\left(\mathrm{Ti}_{0.9} \mathrm{Hf}_{0.1} \mathrm{O}_{2}\right)$ were prepared from oxideroute materials. Pellets were prepared from ball-milled powders (wet and dry milling) by cold pressing, followed by sintering in argon or air for 4 hours at $1275-1400^{\circ} \mathrm{C}$. The samples sintered in argon produced a material composed of up to $90 \mathrm{wt}$ \% pyrochlore, containing most of the $\mathrm{Pu}$ and $\mathrm{U}$ and neutron absorbers, plus a few percent rutile and brannerite (U,Pu) $\mathrm{Ti}_{2} \mathrm{O}_{6}$, and small quantities of $(\mathrm{U}, \mathrm{Pu}) \mathrm{O}_{2}$ (ranging from about $2 \%$ to $<1 \%$, decreasing with increasing sintering temperature). The use of air instead of argon in the sintering step had little effect on the phase assemblage except that it tended to result in the formation of more brannerite. Sample densities were generally in excess of $90 \%$ of theoretical maximum density.

The effect of various processing impurities, specified by LLNL, on the pyrochlore-rich ceramics was also examined. Both $\mathrm{Ce} / \mathrm{U}$ and $\mathrm{Pu} / \mathrm{U}$-doped batches were used for these test fabrications. The major effect of the impurities was to alter the minor phase composition. The major phase, pyrochlore, still dominated the ceramic, with rutile and traces of zirconolite also present in most of the batches tested. In the batches where $\mathrm{Ce}$ was used as an analog for $\mathrm{Pu}$, brannerite was not formed. This indicated that $\mathrm{Pu}$ has a role in stabilizing or promoting the formation of brannerite. 
When Si was present, a minor amount of a silicate-rich phase could be detected in the microstructure, but the overall solid-state reaction was enhanced, inhibiting the formation of brannerite or fluorite-structured oxide. It was not clear whether this silicate phase was crystalline. Other minor phases such as loveringite, magnesium aluminum titanate and magnetoplumbite were detected in some batches. These minor crystalline phases did not appear to be detrimental as far as the overall ceramic aqueous durability is concerned.

In samples where $\mathrm{Cl}$ or $\mathrm{F}$ were added, they were not detected in the final product, except for a barely detectable amount of $F$ in one of the pyrochlore samples. In samples were $2 \mathrm{wt} \%$ of $F$ or $\mathrm{Cl}$ was added to the basic ceramic, $\mathrm{X}$-ray fluorescence analysis (XRF) of the sintered material showed that virtually all of the halides were lost by volatilization. Batches were also made up containing $\mathrm{Na}$ and $\mathrm{K}$. $\mathrm{Na}$, but not $\mathrm{K}$, was incorporated in pyrochlore. XRF results showed that about $20 \%$ of the $\mathrm{Na}$ and all of the $\mathrm{K}$ had volatilized during sintering.

Pellets made from selected batches were leach tested for 7 days at $90^{\circ} \mathrm{C}$ in deionized water, using MCC-1 type test conditions. The leaching behaviors were broadly consistent with those of Synroc-C. The Pu leach rates were approximately $10^{-4} \mathrm{~g} / \mathrm{m}^{2} /$ day and constant to within a factor of 2 for all batches, irrespective of impurity content or preparative method (oxide versus alkoxide process, dry versus wet milling). The leach rates of the $\mathrm{Gd}, \mathrm{Hf}$, and $\mathrm{U}$ were approximately $3,0.1$, and 2 times those of the $\mathrm{Pu}$, indicating that any leached $\mathrm{Pu}$ would be accompanied by significant amounts of neutron absorbers in the near field.

Finally, various samples were heated in argon for about $1 / 2$ an hour at $1000^{\circ} \mathrm{C}$, followed by slow cooling at $1-2^{\circ} \mathrm{C} / \mathrm{min}$. to simulate the effect of adding molten glass to the canned pyrochlore-rich candidate waste forms as envisaged in the can-in-canister design. There were no discernible changes in microstructure, phase assemblage or phase composition in these samples. 
E.R. Vance, M.L. Carter, and R.A. Day, "Interim Report on Task 1.1: Single-Phase Sample Production," 6 pp., R99m022, April 1998 (00256 or 000633).

This report describes efforts to fabricate samples of single-phase zirconolite, pyrochlore and brannerite containing an actinide or cerium. Samples were fabricated using the alkoxide-nitrate process, and then consolidated using either cold pressing and sintering or hot pressing approaches. Highest yields were as follows: $\mathrm{CaZrTi}_{2} \mathrm{O}_{7}$ and $\mathrm{CaHfTi}_{2} \mathrm{O}_{7}, 99 \% ; \mathrm{CaCeTi}_{2} \mathrm{O}_{7}, 99 \%$; $\mathrm{CaUTi}_{2} \mathrm{O}_{7}, 90 \% ; \mathrm{CaThTi}_{2} \mathrm{O}_{7}, 0 \% ; \mathrm{CaPuTi}_{2} \mathrm{O}_{7}, 75 \% ; \mathrm{CeTi}_{2} \mathrm{O}_{6}$, nearly $100 \% ; \mathrm{UTi}_{2} \mathrm{O}_{6}, 98 \%$; $\mathrm{ThTi}_{2} \mathrm{O}_{6}$, nearly $100 \% ; \mathrm{PuTi}_{2} \mathrm{O}_{6}, 75 \%$. The zirconolites $\left(\mathrm{CaZrTi}_{2} \mathrm{O}_{7}\right.$ and $\left.\mathrm{CaHfTi}_{2} \mathrm{O}_{7}\right)$ were relatively easy to prepare and did not require any special efforts. The pyrochlores ( $\mathrm{CaCeTi}_{2} \mathrm{O}_{7}$, $\mathrm{CaUTi}_{2} \mathrm{O}_{7}, \mathrm{CaThTi}_{2} \mathrm{O}_{7}$, and $\mathrm{CaPuTi}_{2} \mathrm{O}_{7}$ ) were generally very difficult to impossible to prepare. The $\mathrm{Ce}$ - and U-pyrochlores were very difficult to form at the stoichiometric composition. The $\mathrm{Pu}$-pyrochlore formed readily, but good yields were difficult to obtain. The Th-pyrohclore did not form at all. The brannerites $\left(\mathrm{CeTi}_{2} \mathrm{O}_{6}, \mathrm{UTi}_{2} \mathrm{O}_{6}, \mathrm{ThTi}_{2} \mathrm{O}_{6}\right.$, and $\left.\mathrm{PuTi}_{2} \mathrm{O}_{6}\right)$ were generally difficult to form. The $\mathrm{Ce}$ - and $\mathrm{Pu}$ - brannerites required long equilibration times. $\mathrm{Th}$-brannerite was readily formed. U-brannerite required atmospheric control. In this case, hot pressing in a graphite die was used. 
M.W.A. Stewart, E.R. Vance, and R.A. Day, "Report on Phase 2 of Task 1.1: Single Phase Synthesis," 74 pp, R99m063, November 1999 (000497).

This report describes the preparation of near single-phase pyrochlores and zirconolites (with $\mathrm{Hf}$ substituted for $\mathrm{Zr}$ ) of the following compositions:

1. Mg-doped zirconolite $\left(\mathrm{Ca}_{0.4} \mathrm{Gd}_{0.6} \mathrm{HfMg}_{0.3} \mathrm{Ti}_{1.7} \mathrm{O}_{7}\right)$

2. Al-doped zirconolite $\left(\mathrm{Ca}_{0.5} \mathrm{Gd}_{0.5} \mathrm{HfAl}_{0.5} \mathrm{Ti}_{1.5} \mathrm{O}_{7}\right)$

3. Ta-doped pyrochlore $\left(\mathrm{CaGdTaTiO}_{7}\right)$

4. Pu-pyrochlore $\left(\mathrm{CaPuTi}_{2} \mathrm{O}_{7}\right)$

5. Zirconolite-4M from the Ca-Gd-Hf-Ti-O system $\left(\mathrm{Ca}_{0.6} \mathrm{Gd}_{0.8} \mathrm{Hf}_{0.6} \mathrm{Ti}_{2} \mathrm{O}_{7}\right.$ and $\left.\mathrm{Ca}_{0.7} \mathrm{Gd}_{0.6} \mathrm{Hf}_{0.7} \mathrm{Ti}_{2} \mathrm{O}_{7}\right)$

All but the Ta-doped pyrochlore were prepared using the alkoxide-nitrate fabrication process. The Ta-doped pyrochlore was prepared using the oxide process.

Samples of the Mg-doped zirconolite, Al-doped zirconolite, Ta-doped pyrochlore and two zirconolite-4M samples from the Ca-Gd-Hf-Ti-O system were shipped to LLNL for further study.

Attempts at preparing a nominally single phase Mo-doped pyrochlore and a Pu-brannerite sample were unsuccessful. The Mo-doped pyrochlore could not be made single-phase with significant amounts (0.4-0.6 formula units) of Mo present in the nominal batch pyrochlore formulation. If $\mathrm{Ca}$ was present, powellite formed, and $\mathrm{Mg}$ produced $\mathrm{MgMoO}_{4}$. All samples basically contained a Ti-pyrochlore with a small amount $(<0.1$ formula units) of Mo present, and a Mo-rich phase, which contained some Ti.

The Pu-brannerite $\left(\mathrm{PuTi}_{2} \mathrm{O}_{6}\right.$ ) proved to be difficult to make. The Pu-brannerite did not form until the sintering temperature was close to the melting point, about $1500^{\circ} \mathrm{C}$. Regions rich in $\mathrm{Pu}$ brannerite could be found in some samples, though these samples invariably contained regions rich in $\mathrm{PuO}_{2}$ and rutile. In a sample with 20 wt. \% excess $\mathrm{TiO}_{2}$, large Pu-brannerite grains were seen, presumably having grown from a melt. 
M.W.A. Stewart, E.R. Vance, R.A. Day, and A. Brownscombe, "Interim Report on Task 1.2: Near Equilibrium Processing Requirements," 209 pp., R99m012, April 1999 (000240).

This report discusses preparation of the following ceramics: the baseline ceramic, the baseline ceramic plus process impurities, a zirconolite-rich composition, a brannerite-rich composition, a composition designed to have about $10 \%$ perovskite in addition to the normal baseline phases, and an approximately $10 \%$ phosphate-doped batch. Hf-Th-U and $\mathrm{Hf}-\mathrm{Pu}-\mathrm{U}$ formulations were used in these preparations. These samples were prepared by the oxide process (via wet or dry milling) and the alkoxide process.

The milling method (dry vs. wet) was found to have a direct effect on the samples. Incomplete milling leads to inhomogeneity in the microstructure. The main effect of incomplete milling is that unreacted actinide oxides remain in the microstructure, usually surrounded by brannerite. The phase composition is also altered, because the actinide is tied up as unreacted oxide. For example, the pyrochlore has less actinide. Also, additional phases, such as zirconolite, may form.

The approach to equilibrium was found to be determined by a number of factors: the efficiency of the milling, the sintering time, the sintering temperature, and the batch composition. The latter was found to be very important; for example, the zirconolite-rich batch had a slower approach to equilibrium than the baseline ceramic, requiring higher sintering temperatures or longer sintering times. The addition of process impurities dramatically altered the approach to equilibrium. The additives produced a silicate liquid phase (at the sintering temperatures), which aided the dissolution and diffusion of the actinide oxide and densification such that even the relatively inhomogeneous dry milled oxide-process samples reached 90 to $95 \%$ of their equilibrium state on sintering at $1350^{\circ} \mathrm{C}$ for 4 hours.

In terms of approach to equilibrium, the following summarizes the results. For samples sintered for 4 hours at $1350^{\circ} \mathrm{C}$ : dry-milled oxide samples reached about 50 to $80 \%$ of their equilibrium state, except for the baseline plus additives batch, which achieved about 90 to $95 \%$ of equilibrium. The wet-milled oxide-process samples reached about 90 to $100 \%$ of equilibrium, and the alkoxide-process samples reached about 95 to $100 \%$ of equilibrium.

The following refers to alkoxide or wet-milled oxide processes. Sintering for 75 hours at $1350^{\circ}$ $\mathrm{C}$ gives about 98 to $100 \%$ of equilibrium. Sintering at $1300^{\circ} \mathrm{C}$ gives about 80 to $95 \%$ of equilibrium. Sintering at $1400^{\circ} \mathrm{C}$ was more difficult to judge as the phase chemistry can change, but generally, the samples sintered for 4 hours at $1400^{\circ} \mathrm{C}$ are similar to the samples sintered for 75 hours at $1350^{\circ} \mathrm{C}$. Generally, the compositions formed the phases that were intended. The exception was the batch aimed at nominally $10 \%$ perovskite, which did not contain perovskite (except for the poorly milled $\mathrm{Th} / \mathrm{U}$ doped batch, and in this case it was due to the Th being retained in large $\mathrm{ThO}_{2}$ grains).

The following apply to the 16-hour wet-milled oxide-process and alkoxide-nitrate process batches sintered at $1350^{\circ} \mathrm{C}$ for 4 hours.

1. The baseline ceramics formed pyrochlore with 10 to 20 vol. $\%$ brannerite and 3 to 5 vol. $\%$ Hf-doped rutile. 
2. The baseline plus impurities ceramics formed pyrochlore with about 15 vol. $\%$ zirconolite$2 \mathrm{M}, 10$ to $20 \mathrm{vol} . \%$ brannerite, 2 to 3 vol. \% Hf-doped rutile and about 1 to 2 vol. $\%$ of an intergranular silicate phase, probably a glass. The impurities led to grain growth, probably via liquid-phase sintering in the samples. The samples warped when sintered at $1350^{\circ} \mathrm{C}$ and above. The additives reduced the effect of the green processing. In these samples, the dry milled oxide-process generally had no unreacted actinide oxide, and even the sample sintered at $1300^{\circ} \mathrm{C}$ for 4 hours contained only a trace of nonreacted $\mathrm{ThO}_{2}$.

3. The zirconolite-rich ceramics formed an approximately equal mixture of zirconolite and pyrochlore with about 15 to 20 vol. \% brannerite and sometimes a little (<5 vol. \%) Hf-doped rutile.

4. The brannerite-rich samples consisted of an approximately equal mixture of brannerite and pyrochlore, and sometimes about 2 to 3 vol. \% Hf-doped rutile was present.

5. The sample designed to contain $10 \%$ perovskite did not actually contain any perovskite. The additional $\mathrm{Ca}$ formed pyrochlore with $\mathrm{Ca}$ content in the $\mathrm{Ca}$ site being close to unity. The additional phases formed depended on whether the sample was Th- or Pu-doped. For Thdoped batches, 5 to 20 vol. $\%$ brannerite and 5 to 10 vol. $\%$ Hf-doped rutile were present. In the $\mathrm{Pu}$-doped samples only about 5 vol. \% rutile was present.

6. The phosphate-doped samples typically consisted of pyrochlore with 15 to 20 vol. \% brannerite, 5 to 10 vol. \% whitlockite and 3 to 7 vol. \% Hf-doped rutile. The whitlockite, nominally $\mathrm{Ca}_{3}\left(\mathrm{PO}_{4}\right)_{2}$, contained $\mathrm{Gd}, \mathrm{Hf}, \mathrm{U}, \mathrm{Th}$, and $\mathrm{Ti}$.

The results of the $\mathrm{Pu} / \mathrm{U}$-doped samples were similar to those for the $\mathrm{Th} / \mathrm{U}$-doped samples. The $\mathrm{Th} / \mathrm{U}$-doped samples had similar phase compositions to the $\mathrm{Pu} / \mathrm{U}$-doped samples, which indicates that $\mathrm{Th}$ is a good surrogate for $\mathrm{Pu}$ in the phase assemblages studied. The major exception was that the Th has a greater tendency to form brannerite and hence, the Th-doped ceramics tend to have more brannerite. The $\mathrm{Pu}, \mathrm{U}$, and Th partitioned as expected, mainly into the pyrochlore, brannerite, and zirconolite phases. Some also entered the whitlockite. The amounts in the minor phases (rutile, glass and whitlockite) were small, and the neutron absorbers Hf and Gd were also found in these phases. 
M.W.A. Stewart, E.R. Vance, R.A. Day, T. Eddowes, and S. Moricca, "Interim Report on Task 1.2: Near Equilibrium Processing Requirements- Attrition Milling,” 107 pp., R00m012, April $2000(000651)$.

In previous work, the objectives of the near equilibrium processing work had only partly been achieved as the work on $\mathrm{Hf}-\mathrm{Pu}-\mathrm{U}$-formulations and to a significant degree on $\mathrm{Hf}-\mathrm{Th}-\mathrm{U}$ formulations has been performed under grinding/blending conditions that did not replicate plant-like fabrication processes, particularly in the case with the small glove-box attritor. Nevertheless the results do show that actinide-rich particles, not present in specimens made via the alkoxide-route (equilibrium conditions), occur when the grinding process is not efficient enough to ensure that high-fired $\mathrm{PuO}_{2}$, $\mathrm{ThO}_{2}$ and $\mathrm{UO}_{2}$ particles are below a critical size. The current perception is that the critical size for specimens sintered at $1350^{\circ} \mathrm{C}$ for 4 hours is about $5 \mu \mathrm{m}$ in diameter.

Our larger scale attritor experiments as well as experience with wet and dry ball milling suggests that acceptable mineralogy and microstructure can be obtained by dry milling via attritor and ball mills. This is provided that appropriate attention is paid to the size and density of the grinding media, grinding additives that reduce caking of the powder, and in the case of attritors the grinding speed and pot setup.

The ideal products for sintering are free flowing granules of $\sim 100 \mu \mathrm{m}$ containing constituents ground to about $1 \mu \mathrm{m}$ to ensure homogeneity and equilibrium mineralogy.

The following six ceramic formulations were examined in this attrition milling study:

- Zr-Ce-Ce, Hf-Th-U, and Hf-Pu-U baseline

- Hf-Th-U baseline ceramic plus process impurities

- Hf-Th-U doped zirconolite-rich composition

- Hf-Th-U doped brannerite-rich composition

- Hf-Th-U-doped composition originally designed to have $\sim 10 \%$ perovskite in addition to the normal baseline phases

- $\sim 10 \%$ phosphate Hf-Th-U doped batch.

These samples were prepared by oxide-route via wet and/or dry attrition milling.

Preliminary work with the $\mathrm{Zr}$-Ce-Ce baseline formulation indicated that dry ball milling could be successfully carried out in large pots $(750-1500 \mathrm{cc})$ with $5 \mathrm{~mm}$ diameter zirconia media. When the small $110 \mathrm{cc}$ quick-change pots with $2 \mathrm{~mm}$ diameter media were used, the initial results for dry attrition milling of $\mathrm{Th} / \mathrm{U}$-doped were not successful. The powder tended to form a cake on the bottom of the mill pot (this is sometimes referred to as a foot) and on the walls of the pot. By the combination of breaking up this cake every 10 minutes (called 1 pass), increasing the mill speed, modifying the milling pot and using additives to aid milling we were able to successfully dry attrition mill $\mathrm{Th} / \mathrm{U}$ and Pu/U-doped samples in the small pot.

The efficiency of the milling method has a direct effect on the final sintered samples. Incomplete milling leads to an inhomogeneous microstructure. The main effects of incomplete milling are:

a) Unreacted actinide oxides remain in the microstructure, usually surrounded by brannerite. The 
phase composition also alters due to the actinide being tied up in the unreacted oxide, e.g., the pyrochlore has less actinide, and additional phases such as zirconolite may form because of this or localised inhomogeneity.

b) Incomplete breakup of the "large" agglomerates in the green powder produces porosity.

c) Localised concentrations of uranium oxide can produce porosity, particularly if it has been calcined in air and later releases oxygen on sintering.

Overall, the attrition milled samples produce comparable results to the wet and dry ball milled samples of the same composition. The phases formed in samples of each of the compositions tested were the same as the ball milled samples. The formulations formed the phases expected/nominated when attrition milled. The exception was the nominally $\sim 10 \%$ perovskite batch, which did not form perovskite (the same result occurred in the ball milled samples). The baseline ceramics, essentially formed pyrochlore as the main phase with $10-20$ vol. $\%$ brannerite and $\sim 5$ vol. $\% \mathrm{Hf}$-doped rutile. When impurities were added, zirconolite-2M and a silicate phase formed. The zirconolite-rich ceramics and brannerite-rich samples were as expected richer in zirconolite and brannerite than the baseline. The phosphate doped samples were similar to the baseline except that they contained the phosphate phase whitlockite (nominally, $\left.\mathrm{Ca}_{3}\left(\mathrm{PO}_{4}\right)_{2}\right)$. The partitioning of the elements in the attrition milled samples is the same as in the ball milled samples. The U, Pu and Th partitioned as expected mainly into the pyrochlore, brannerite and zirconolite. The amounts in the minor phases, rutile and whitlockite, were small. The Th/U-doped dry attrition milled samples contained some residual $\mathrm{ThO}_{2}$. In these samples, the $\mathrm{UO}_{2}$ appears to have completely reacted with the precursor elements to form brannerite and pyrochlore. The only $\mathrm{UO}_{2}$ detected was in the very poorly milled batches. The $\mathrm{ThO}_{2}$ is present in poorly milled samples as large "unreacted" lumps. In most samples, some actinide oxide regions can be found at the center of some brannerite grains.

Pu-doped sintered samples $\left(1350^{\circ} \mathrm{C} / 4\right.$ hours/air) were made from dry attrition milled baseline powder. These samples all contained some $\mathrm{PuO}_{2}$. The amount of $\mathrm{PuO}_{2}$ decreased with the milling time/number of passes through the mill. The sample milled for 10 minutes ( 1 pass) contains $\mathrm{PuO}_{2}$ grains up to $\sim 100 \mu \mathrm{m}$ across. These are surrounded by a thin layer of brannerite. The microstructure of the samples becomes more homogeneous as the milling time/number of passes increases, with the porosity decreasing as the $\mathrm{PuO}_{2}$ and precursor element agglomerates are progressively milled to a smaller size. After 100 minutes dry attrition milling (10 passes) residual $\mathrm{PuO}_{2}$ is present mainly as small regions inside brannerite grains with a few residual grains $\sim 20 \mu \mathrm{m}$ across. The Pu-doped samples are comparable to previous dry ball milled samples except that they appear to be more porous. This may in part be due to burnout of the organic milling aids added to assist this dry attrition milling.

The attrition milling results show that dry attrition milling is a feasible process. Many of the problems encountered were in part due to the need to scale down the attrition milling to handle the radioactive batches, particularly the Pu-doped batches. Dry attrition milling of large non-radioactive batches was very successful. 
D.S. Perera, R.A. Day, M.W.A. Stewart, and E.R. Vance, "Interim Report on Task 1.3: Equilibrium Phase Diagram," 90 pp., R99m021, April 1999 (000255 or 000640).

This report describes the preparation of twenty-four compositions in the $\mathrm{CaHfTi}_{2} \mathrm{O}_{7}-\mathrm{Gd}_{2} \mathrm{Ti}_{2} \mathrm{O}_{7}-$ $\mathrm{CaAnTi}_{2} \mathrm{O}_{7}$ pseudo-ternary system, where $\mathrm{An}=\mathrm{Ce}, \mathrm{Th}, \mathrm{U}$, and $\mathrm{Pu}$. Samples were prepared using the alkoxide-nitrate process. The Ce-containing series was sintered at $1300^{\circ} \mathrm{C}$ and $1500^{\circ} \mathrm{C}$. The Th- and U-containing series were sintered at $1300^{\circ} \mathrm{C}$ and $1400^{\circ} \mathrm{C}$. The Pu-containing series was sintered only at $1400^{\circ} \mathrm{C}$. The $\mathrm{Ce}$ and Th series were sintered in air, and the others were sintered in an $\mathrm{Ar}$ atmosphere. The samples were analyzed by $\mathrm{x}$-ray diffraction, scanning electron microscopy, and energy-dispersive $\mathrm{x}$-ray spectrometry. The samples contained mostly zirconolite, pyrochlore, rutile and perovskite, depending on the compositions and the sintering temperature. In some samples, small amounts of brannerite and hafnium titanate were observed. Based on the phase distribution, the zirconolite-pyrochlore phase boundaries were ascertained for each series and were marked on the pseudo-ternary diagram for $\mathrm{CaHfTi}_{2} \mathrm{O}_{7}-\mathrm{Gd}_{2} \mathrm{Ti}_{2} \mathrm{O}_{7-}$ $\mathrm{CaAnTi}_{2} \mathrm{O}_{7}$. It was similar for all and divides the end-members zirconolite and pyrochlore at approximately a 40:60 molar ratio. 
M.W.A. Stewart, E.R. Vance, and R.A. Day, "Supplement to Interim Report on Task 1.3:

Equilibrium Phase Diagram," 20 pp., R99m023, April 1999 (000257)

This report summarizes results generated on the $\mathrm{CaHfTi}_{2} \mathrm{O}_{7}-\mathrm{Gd}_{2} \mathrm{Ti}_{2} \mathrm{O}_{7}$ system. Samples were made using the alkoxide-nitrate process. Sintering was performed on $\mathrm{Pt}$ foil in air at $1500^{\circ} \mathrm{C}$ for 100 hours. Analyses were carried out by $x$-ray diffraction and scanning electron microscopy, with energy-dispersive $\mathrm{x}$-ray spectrometry used for quantitative analysis.

It was found that there are well-defined transition zones with zirconolite-4M appearing in the $\mathrm{Ca}_{0.45} \mathrm{Gd}_{1.1} \mathrm{Hf}_{0.45} \mathrm{Ti}_{2} \mathrm{O}_{7}$ sample and zirconolite-2 $\mathrm{M}$ appearing in the $\mathrm{Ca}_{0.8} \mathrm{Gd}_{0.4} \mathrm{Hf}_{0.8} \mathrm{Ti}_{2} \mathrm{O}_{7}$ sample. For the zirconolite composition $\left(\mathrm{Ca}_{z} \mathrm{Gd}_{y} \mathrm{Hf}_{\mathrm{x}} \mathrm{Ti}_{2} \mathrm{O}_{7}\right)$, the $4 \mathrm{M}$ polytype covers the approximate range $0.5<x<0.66$. The $2 \mathrm{M}$ polytype occurs for $\mathrm{x}>0.8$.

The pyrochlore composition was close to the design composition. The maximum amount of Hf measured in the pyrochlore in the samples was 0.42 formula units.

Excess rutile samples showed some zoning around the edges of the grains. This was not observed in samples without excess rutile.

The rutile incorporated some hafnium and hence, in samples made with excess titania, the pyrochlore and zirconolite were deficient in hafnia, relative to the design composition. Except near the zirconolite end of the test spectrum, where the rutile had slightly more $\mathrm{Hf}$, the rutile composition was relatively constant at a stiochiometry of about $\mathrm{Hf}_{0.1} \mathrm{Ti}_{0.9} \mathrm{O}_{2}$. The rutile in samples made with excess titania had slightly less $\mathrm{Hf}$. 
D.S. Perera, M.W.A. Stewart, R.A. Day, A. Brownscombe, and E.R. Vance, "Update of Interim . Report on Task 1.3: Equilibrium Phase Diagram," 19 pp., R99m037, July 1999 (000711)

Four different samples of composition $\mathrm{Ca}_{0.65} \mathrm{Hf}_{0.3} \mathrm{An}_{0.35} \mathrm{Gd}_{0.7} \mathrm{Ti}_{1.9} \mathrm{O}_{6.8}$, where $\mathrm{An}=\mathrm{Ce}, \mathrm{Th}, \mathrm{U}$, and $\mathrm{Pu}$, were prepared using an alkoxide-nitrate fabrication route. The Ce-containing sample was sintered at $1500^{\circ} \mathrm{C}$ for $96 \mathrm{~h}$ in air, the Th-containing sample was sintered at $1400^{\circ} \mathrm{C}$ for $16 \mathrm{~h}$ in air, and the other samples were sintered at $1400^{\circ} \mathrm{C}$ for $16 \mathrm{~h}$ in argon. Pyrochlore was the major phase in all of the samples. Hf-bearing rutile was the minor phase in all the samples except the $\mathrm{Pu}$-containing sample, which contained a minor amount of perovskite. The zirconolitepyrochlore phase boundary remains the same as previously reported. 
D.S. Perera, R.A. Day, M.W.A. Stewart, and E.R. Vance, "Interim Report on Task 1.3: Equilibrium Phase Diagram," 52 pp., R99m065, November 1999 (000496)

To determine the phase equilibria in the pseudo-ternary systems $\mathrm{CaHfTi}_{2} \mathrm{O}_{7}-\mathrm{Gd}_{2} \mathrm{Ti}_{2} \mathrm{O}_{7}-\mathrm{Al}_{2} \mathrm{TiO}_{5}$ and $\mathrm{CaHfTi}_{2} \mathrm{O}_{7}-\mathrm{Gd}_{2} \mathrm{Ti}_{2} \mathrm{O}_{7}-\mathrm{MgTi}_{2} \mathrm{O}_{5}$, five compositions containing $10 \mathrm{~mol} \%$ additions of $\mathrm{Al}_{2} \mathrm{TiO}_{5}$ and $\mathrm{MgTi}_{2} \mathrm{O}_{5}$ respectively, were initially prepared using an alkoxide-nitrate fabrication route. The samples were sintered at temperatures ranging from 1300 to $1400^{\circ} \mathrm{C}$ in an air atmosphere. The sintered samples were analyzed by X-ray diffraction, scanning electron microscopy, and energy dispersive X-ray spectrometry. Both Al and Mg have approximately the same effect on the binary pyrochlore-zirconolite system. Perovskite was observed in the Al-containing system but was not observed in the Mg-containing system. In the Mg-containing system, the phase region of pyrochlore and zirconolite is much smaller than in the Al-containing system. However, only zirconolite- $2 \mathrm{M}$ (except for a trace of zirconolite- $4 \mathrm{M}$ in two systems) was observed. This is in contrast to the previous work on the pseudo-binary system $\mathrm{CaHfTi}_{2} \mathrm{O}_{7}-\mathrm{Gd}_{2} \mathrm{Ti}_{2} \mathrm{O}_{7}$, where zirconolite was also present in many samples. Tentative phase boundaries have been marked for both systems. Compositions further away from the pseudo-binary system $\mathrm{CaHfTi}_{2} \mathrm{O}_{7}-\mathrm{Gd}_{2} \mathrm{Ti}_{2} \mathrm{O}_{7}$ have been prepared to better define the phase boundaries. 
D. S. Perera, R. A. Day, M. W. A. Stewart, and E. R. Vance, "Interim Report on Task 1.3: Equilibrium Phase Diagram," 44 pp., R00m015, March 2000 (000649).

To determine the phase equilibria at approximately $1350^{\circ} \mathrm{C}$ in the pseudo-ternary systems $\mathrm{CaHfTi}_{2} \mathrm{O}_{7}-\mathrm{Gd}_{2} \mathrm{Ti}_{2} \mathrm{O}_{7}-\mathrm{Al}_{2} \mathrm{TiO}_{5}$ and $\mathrm{CaHfTi}_{2} \mathrm{O}_{7}-\mathrm{Gd}_{2} \mathrm{Ti}_{2} \mathrm{O}_{7}-\mathrm{MgTi}_{2} \mathrm{O}_{5}$ sixteen compositions were prepared using an alkoxide-nitrate fabrication route. In this work, eleven compositions for each system were sintered at $1400^{\circ} \mathrm{C}$ in air for 16 hours. The sintered samples were analyzed by X-ray diffraction, scanning electron microscopy, and energy dispersive X-ray spectroscopy. Tentative phase boundaries have been marked for both systems based on the phases observed. However, one or two phase regions have been marked which did not contain a composition that was investigated. The phase regions have been marked to be consistent with the Gibbs' Phase Rule.

The zirconolite-4M polymorph was more prevalent in the $\mathrm{Mg-containing} \mathrm{system} \mathrm{than} \mathrm{in} \mathrm{the} \mathrm{Al-}$ containing system. Another zirconolite polymorph was observed in both systems. It was confirmed by transmission electron microscopy and work to identify this polymorph is continuing. There were slight differences in the phase distributions between the two systems but in general they were very similar. Perovskite and $\mathrm{Hf}$-containing rutile were observed in both systems as well as pyrochlore, zirconolite, and pseudobrookite $\left(\mathrm{Al}_{2} \mathrm{TiO}_{5}\right) / \operatorname{armalcolite}\left(\mathrm{MgTi}_{2} \mathrm{O}_{5}\right)$ 
B. D. Begg; M. Mestre, R. A. Day, and E. R. Vance, "Task 1.3: Equilibrium Phase Diagram Phase 3(ii): Phase Equilibria in the $\mathrm{TiO}_{2}$-rich portion of the $\mathrm{CaO}-\mathrm{AnO}_{2}-\mathrm{TiO}_{2}$ Ternary $(\mathrm{An}=\mathrm{Ce}$, Th, U, or Pu)" 11 pp., R00m026, April 2000 (000672).

A maximum of four compounds exist in the $\mathrm{TiO}_{2}$-rich region of the $\mathrm{CaO}-\mathrm{AnO}_{2}-\mathrm{TiO}_{2}$ ternary system and these are brannerite $\left(\mathrm{AnTi}_{2} \mathrm{O}_{6}\right)$ pyrochlore $\left(\mathrm{CaAnTi}_{2} \mathrm{O}_{7}\right)$ perovskite $\left(\mathrm{CaTiO}_{3}\right)$ and rutile $\left(\mathrm{TiO}_{2}\right)$. Of these, the two principal actinide-bearing compounds are brannerite and pyrochlore. In this study we have investigated the effect of small compositional deviations, $10 \%$ by weight, around the end-member brannerite and pyrochlore compositions towards the other known compounds in the ternary system. A list of these sample compositions, for any given ion, investigated as part of this study is listed in Table I. In addition, the effect of small combined equimolar additions $(\sim 5 \mathrm{~mol} \%)$ of $\mathrm{Ca}$ and $\mathrm{An}$ in rutile were also examined. Samples were prepared by sintering in air at 1300 to $1400^{\circ} \mathrm{C}$.

Table I. Compositions investigated as part of Task 1.3, phase 3(II), where $\mathrm{An}=\mathrm{Ce}, \mathrm{Th}, \mathrm{U}$ and $\mathrm{Pu}$.

\begin{tabular}{cc}
\hline Brannerite & Pyrochlore \\
\hline $100 \% \mathrm{AnTi}_{2} \mathrm{O}_{6}$ & $100 \% \mathrm{CaAnTi}_{2} \mathrm{O}_{7}$ \\
$90 \% \mathrm{AnTi}_{2} \mathrm{O}_{6}+10 \% \mathrm{CaTiO}_{3}$ & $90 \% \mathrm{CaAnTi}_{2} \mathrm{O}_{7}+10 \% \mathrm{CaTiO}_{3}$ \\
$90 \% \mathrm{AnTi}_{2} \mathrm{O}_{6}+10 \% \mathrm{TiO}_{2}$ & $90 \% \mathrm{CaAnTi}_{2} \mathrm{O}_{7}+10 \% \mathrm{TiO}_{2}$ \\
$90 \% \mathrm{AnTi}_{2} \mathrm{O}_{6}+10 \% \mathrm{CaAnTi}_{2} \mathrm{O}_{7}$ & $90 \% \mathrm{CaAnTi}_{2} \mathrm{O}_{7}+10 \% \mathrm{AnTi}_{2} \mathrm{O}_{6}$ \\
\hline
\end{tabular}


M.W.A. Stewart, E.R. Vance, and R.A. Day, "Interim Report on Task 1.4: Impurity Effects," 88 pp., R99m011, February 1999 (000204).

This report describes work directed toward determining to what degree different impurity elements in the ceramic for plutonium immobilization can be considered as equivalent to one another, and can thus be treated together in groups in terms of the formulation of the ceramic.

Except for $\mathrm{Pu}$-containing samples, which were made by the oxide process, all samples were made using the alkoxide-nitrate process. Sintering was performed at $1350^{\circ} \mathrm{C}$ for four hours using various atmospheres. Densities were measured by the Archimedes method. Analysis was performed by $x$-ray diffraction and by scanning electron microscopy with energy-dispersive $\mathrm{x}$ ray analysis.

From work with baseline ceramics containing $\mathrm{Pu}$, or $\mathrm{Ce}$ substituted for $\mathrm{Pu}$, doped with sets of nonradioactive impurity ions (with supposedly the same valency) and sintered in different atmospheres, the conclusion was that all ions of similar size and valency are indeed crystalchemically equivalent, unless there are volatility problems. However, the real question appears to be what the appropriate valency states of the multivalent impurity ions are under given sintering conditions. For example, when sintered in highly reducing atmospheres (such as $3.7 \%$ hydrogen in argon), $\mathrm{Mo}, \mathrm{W}, \mathrm{Zn}, \mathrm{Fe}, \mathrm{Cu}, \mathrm{Co}$, and $\mathrm{Ni}$ are all reduced to the metallic state.

The partitioning across the different phases present was not even. The elements from the nominal $2+, 3+, 4+, 5+$, and $6+$ families partitioned preferentially or resulted in the formation of new phases if sufficient amounts were present. If the phases of the baseline ceramic (pyrochlore, zirconolite, brannerite and rutile) were saturated with these ions, new phases formed to take up the excess impurity ions. Additional phases in this work included ulvospinel, perovskite, magnetoplumbite, loveringite-like phases, metallic alloys and powellite/scheelite.

The $\mathrm{Pu}$ - and $\mathrm{Ce}$-doped samples gave similar results to each other. While samples sintered in air were similar in terms of phases present (with some variations, which are discussed in the text), there were differences in the compositions of the phases.

In summary, the (probably) divalent ions $\mathrm{Mn}, \mathrm{Fe}, \mathrm{Co}, \mathrm{Ni}$ and $\mathrm{Mg}$ behaved similarly, but certainly $\mathrm{Cu}$, and possibly $\mathrm{Zn}$, showed some volatility losses. $\mathrm{Al}, \mathrm{Ga}, \mathrm{Cr}$, trivalent $\mathrm{Fe}$ and $\mathrm{Mn}$ all behaved similarly to each other. However, Sn was converted to the metallic state in reducing atmospheres. $\mathrm{Nb}$ and $\mathrm{Ta}$ were equivalent. Mo and $\mathrm{W}$ behaved equivalently otherwise, but displayed significantly different partitioning ratios between the pyrochlore and scheelite/powellite phases; both reduced to metal in hydrogenous atmospheres. The authors contend that $\mathrm{V}$ was pentavalent to at least some extent even in Ar atmospheres, and acted as a flux. Of the glass formers, $\mathrm{Al}$ was not equivalent to $\mathrm{B}$, as the $\mathrm{Al}$ tended to enter the crystalline phases and promoted the formation of zirconolite, whereas $B$ was a much stronger glass former. $\mathrm{Na}$ was not equivalent to $\mathrm{K}$. Addition of $\mathrm{Na}$ promoted the formation of a $\mathrm{Na}$-Ce perovskite when the ceramics were sintered in argon, and $\mathrm{Na}$ also entered the pyrochlore, zirconolite and glass. $\mathrm{K}$ was found only in the glass. Both $\mathrm{K}$ and $\mathrm{Na}$ were believed to be partially volatile under the sintering conditions tested. 


\section{ANL Reports}

The following two reports provided by ANL have been summarized: - Characterization and Corrosion Behavior of Hafnium-Cerium-Uranium Ceramics Containing
Impurities

- Fissile Materials Disposition Formulation Report 
Allen J. Bakel, Edgar C. Buck, Vladislav N. Zyryanov, Carol J. Mertz, and David B. Chamberlain, "Characterization and Corrosion Behavior of Hafnium-Cerium-Uranium Ceramics Containing Impurities," 44 pp., ANL-99/xx, PIP-99-077, June 1999 (000356).

This report describes studies covering the effects of impurities on the phase assemblage and the corrosion behavior of the baseline ceramic formulation for plutonium immobilization.

Samples that had been fabricated at LLNL by the oxide process, followed by cold-pressing and sintering, were shipped to ANL. They were examined by scanning electron microscopy with energy-dispersive $\mathrm{x}$-ray spectrometry and by transmission electron microscopy.

The major phases found in the ceramics in this study were pyrochlore, zirconolite, brannerite and rutile. The composition of each of these phases was remarkably consistent throughout this series of ceramics. The baseline ceramic formulation contained only the four major phases. The addition of impurity elements to the ceramic composition resulted in the formation of minor phases in some of the ceramics, and in the suppression of brannerite and/or rutile in some of the ceramics.

The addition of $0.43 \mathrm{wt} . \%$ or more $\mathrm{Al}$ appeared to lead to the formation of a crystalline Al-Ca-Ti oxide phase. The composition of this phase was approximately 30 mass $\% \mathrm{Al}, 5$ mass $\% \mathrm{Ca}, 10$ mass $\% \mathrm{Ti}, 20$ mass $\% \mathrm{Ce}$, and 5 mass $\% \mathrm{U}$.

The addition of a complex impurity mixture that included alkalai metals, alkaline earth elements, $\mathrm{B}$ and $\mathrm{Si}$ led to the formation of an amorphous silicate phase. The composition of this phase was found to be somewhat variable. In addition to $\mathrm{Al}, \mathrm{Si}$, and $\mathrm{P}$, the silicate phase contained $\mathrm{U}, \mathrm{Ca}$, $\mathrm{Ti}, \mathrm{Ce}$, and $\mathrm{Gd}$.

The inclusion of 7.7 mass $\%$ of the complex impurity mixture in ceramic A-8 resulted in the formation of perovskite in addition to the silicate and Al-Ca-Ti oxide phases. The additional $\mathrm{Ca}$, added as $\mathrm{CaCl}_{2}$ and $\mathrm{CaF}_{2}$, may have led to the formation of the perovskite. The addition of the complex impurity mixture apparently inhibited the formation of brannerite and rutile.

$\mathrm{MCC}-1$ corrosion tests were performed. It was found that the presence of a crystalline $\mathrm{Al}-\mathrm{Ca}-\mathrm{Ti}$ oxide phase led to a small increase in the $\mathrm{Ca}$ release relative to release from ceramics containing only pyrochlore, zirconolite, rutile, and brannerite. The presence of the amorphous silicate phase led to a significant increase in the $\mathrm{Ca}$ and $\mathrm{Ce}$ release, and the presence of perovskite led to a large increase in $\mathrm{Ca}$ release. In addition, the absence of brannerite appeared to result in a decrease in the $U$ release. 
M.C. Hash, V.N. Zyryanov, J.K. Basco, and D.B. Chamberlain, "Fissile Materials Disposition Formulation Report," 58 pp., ANL-99/xx, Argonne National Laboratory, June 1999 (000498).

This report describes the fabrication and characterization of the baseline ceramic and ten other formulations covering various extreme cases of impurities. These samples were produced for the purposes of studying the effects of the impurities on the fabrication and of supplying samples to be used in later corrosion studies to determine the effects of the impurities on the release behavior of plutonium and neutron absorbers.

The initial fabrication procedure was supplied by LLNL but was modified slightly at ANL to suit the available equipment. It was found that carbon impurity in the uranium oxide starting material was a significant parameter. In the ball milling step, a high ratio of water to powder was used, and the mixing time was extended to 16 hours. Calcining was performed in air at $750^{\circ} \mathrm{C}$ for 1 hour, and sintering was performed in argon at $1350^{\circ} \mathrm{C}$ for 4 hours.

Bulk densities and porosities were evaluated. Observed densities ranged from a high of about 5.6 $\mathrm{g} / \mathrm{cm}^{3}$ to a low of $4.4 \mathrm{~g} / \mathrm{cm}^{3}$. Most samples had a density greater than $5.2 \mathrm{~g} / \mathrm{cm}^{3}$. The microstructure and phase assemblage of the samples were characterized using scanning electron microscopy with energy-dispersive $\mathrm{x}$-ray spectrometry and also using $\mathrm{x}$-ray diffraction.

Major phases observed were pyrochlore, brannerite, zirconolite, and rutile. Other minor phases included perovskite, silicate, phosphate, and actinide oxide. The presence of and abundance of the minor phases was highly dependent upon the composition of the sample. One sample was designed to contain only glass of about the same composition as the residual glass that occurs in the ceramic when there is silica impurity. The glass was successfully prepared and remained amorphous as long as it was cooled fairly quickly after fabrication.

In most samples there was a small amount of residual actinide oxide. It is believed to be a reaction product rather than non-reacted raw material. There were two reasons for this conclusion: (1) the phase is a mixture of uranium and plutonium oxide, and (2) the presence of the phase is dependent upon the starting material composition and not upon the process techniques. The actinide oxide is always found within the brannerite grains. 


\section{LLNL Reports}

The following three reports provided by LLNL have been summarized:

- Development of a Ceramic Form for the Immobilization of Excess Plutonium

- Pyrochlore-rich Titanate Ceramics for the Immobilization of Plutonium: Redox Effects on Phase Equilibria in Cerium- and Thorium-substituted Analogs

- Saturation of Impurity-rich Phases in a Cerium-substituted Pyrochlore-rich Titanate Ceramic: Part 1. Experimental Results 
Bartley B. Ebbinghaus, Oscar H. Krikorian, and Richard A. Van Konynenburg, "Development of a Ceramic Form for the Immobilization of Excess Plutonium," 104 pp, UCRL-ID-xxxxx, Lawrence Livermore National Laboratory, Livermore, CA, June 2000 (000708).

This report describes the immobilization form development work performed at LLNL starting from the beginning of the Plutonium Immobilization Project until December, 1999. Early on, a small amount of work was performed to investigate a variety of possible phase assemblages that were based on natural mineral analogs. Among others, this included zircon and monazite. Because of the extensive past experience with the titanate-based family of ceramics (called Synroc) in nuclear and mixed wastes management research and development, and the urgency of the project schedule in response to the "clear and present danger" presented by excess weaponsusable plutonium, efforts were soon focused on the titanate-based ceramics.

Samples were made for a variety of purposes. They include investigative studies on the initial form and process, basic formulation and process parameters, form qualification samples and data, and process control model development.

Samples were characterized mainly by geometric bulk density measurement, $\mathrm{x}$-ray diffraction analysis and scanning electron microscopy with energy dispersive $\mathrm{x}$-ray analysis. $\mathrm{X}$-ray fluorescence analysis was used on a few samples, and electron microprobe analysis was used on a large number of samples, including all those incorporating plutonium.

The initial work was performed on a zirconolite-based ceramic, taking advantage of the work that had been performed on Synroc. In this formulation, $\mathrm{Gd}$ was added as a neutron absorber to prevent criticality in the product. In these studies, it was shown that "high-fired" plutonium oxide, 20 microns in diameter or less, could be incorporated into a zirconolite-rich ceramic. It was also shown that this ceramic is not affected by a heating cycle similar to that created during the pour of HLW glass in the DWPF. The effect of various impurities was also studied for this original formulation.

As it became clear that considerable uranium was expected to be present in the feed streams along with the plutonium, the formulation was changed to a pyrochlore-based ceramic, which was capable of incorporating higher actinide contents. Pyrochlore was also belived to be more resistant to radiation damage effects than zirconolite. It was decided to use both $\mathrm{Gd}$ and $\mathrm{Hf}$ as neutron absorbers for extra assurance of criticality safety. Various fabrication methods were studied, and the oxide process combined with cold-pressing and sintering was chosen as the most practicable for glovebox operation. Most of the samples made were cerium analogs, but a large number of Pu-containing samples, as well as a few thorium analogs, were also fabricated.

The basic formulation and process parameters studies investigated near-equilibrium process conditions, sintering aids, and process parameters. Alkoxide-nitrate, wet milling, and dry milling techniques were used in the near-equilibrium studies. The alkoxide-nitrate and wet milling fabrication processes produced well reacted products. The samples made by dry milling produced samples that were not as well reacted and had lower densities. The sintering aid studies showed that the type of $\mathrm{TiO}_{2}$ used made a difference in the product density. Anatase consistently made samples of higher density than rutile. Small amounts of most impurities generally 
increased the product density whereas large amounts of impurities generally reduced the product densities. One of the best sintering aids was $\mathrm{Al}_{2} \mathrm{O}_{3}$. The process parameter studies showed that $\mathrm{Ca}(\mathrm{OH})_{2}$ is preferred to $\mathrm{CaCO}_{3}$ as the starting material for $\mathrm{CaO}$. In all cases, samples made with $\mathrm{CaCO}_{3}$ had lower densities than samples made with $\mathrm{Ca}(\mathrm{OH})_{2}$.

The sample suite for form qualification and performance data involved the preparation of single phase samples and process and compositional extreme samples. Single phases of U-brannerite and U-pyrochlore were prepared. Successful preparation of the U-brannerite required heat treatment of the loose powder for 300 hours in $5 \% \mathrm{CO} / \mathrm{CO}_{2}$ where the material was removed and reground every 50 hours. U-pyrochlore was prepared by making an off stoichiometric composition of approximately $\mathrm{Ca}_{1.46} \mathrm{U}_{0.69} \mathrm{Ti}_{1.85} \mathrm{O}_{7}$. The process and compositional extreme samples fabricated for durability testing included a zirconolite-rich formulation, a brannerite-rich formulation, and a variety of samples with various levels of impurities.

In the process control model development studies, samples were prepared to test the effects of impurities. Some of the impurities studied extensively in this work were $\mathrm{V}_{2} \mathrm{O}_{3}, \mathrm{BaO}, \mathrm{MoO}_{3}$, $\mathrm{WO}_{3}, \mathrm{Cr}_{2} \mathrm{O}_{3}, \mathrm{Ga}_{2} \mathrm{O}_{3}, \mathrm{Nb}_{2} \mathrm{O}_{5}$, and $\mathrm{Ta}_{2} \mathrm{O}_{5}$. At the levels expected in the plutonium feeds, none of these impurities pose any concern. Very high levels of impurities were generally required before any detrimental effects were observed. Addition of about $1.5 \mathrm{wt}$ percent $\mathrm{V}_{2} \mathrm{O}_{3}$ to the ceramic formulation caused melting in the ceramic at $1400^{\circ} \mathrm{C}$. Addition of $\mathrm{V}_{2} \mathrm{O}_{3}$ also caused the formation of an unknown phase $\mathrm{CaCeV}_{2} \mathrm{O}_{8}$ in the $\mathrm{Hf}-\mathrm{Ce}-\mathrm{U}$ samples. Addition of about $0.5 \mathrm{wt}$ percent $\mathrm{BaO}$ caused a slight amount of melting at $1350^{\circ} \mathrm{C}$. Also formed was a Ba-titanate phase of the approximate composition $\mathrm{BaTi}_{4} \mathrm{O}_{9}$. Addition of about 2.9 wt percent $\mathrm{MoO}_{3}$ or more, caused the formation of powellite $\left(\mathrm{CaMoO}_{4}\right)$ and addition of about $12.8 \mathrm{wt}$ percent $\mathrm{WO}_{3}$ or more, caused the formation of scheelite $\left(\mathrm{CaWO}_{4}\right)$. Although $\mathrm{MoO}_{3}$ was accommodated well in the baseline formulation, the fabricated pellets were of low density when sintered in air. It is believed that the low density of these pellets was cased by the volatilization of $\mathrm{MoO}_{3}$ at or near the sintering temperature. The $\mathrm{Cr}_{2} \mathrm{O}_{3}$ impurity was accommodated primarily in the rutile phase. The $\mathrm{Ga}_{2} \mathrm{O}_{3}$ impurity was accommodated in zirconolite unless greater than about 6.3 wt percent was added, then the $\mathrm{Ga}_{2} \mathrm{O}_{3}$ form a Ga-titanate. Any quantity of $\mathrm{Nb}_{2} \mathrm{O}_{5}$ and $\mathrm{Ta}_{2} \mathrm{O}_{5}$ added was accommodated in pyrochlore. No accessory phases were formed when either of these impurities was added.

In summary, the pyrochlore-based ceramic form is ready for full scale testing in plant prototypic processes. As long as the mixing of the feed materials is intimate, the product densifies and reacts well. A number of compositions have been prepared and are now available for various form qualification studies, and at the levels of impurities expected, there are no detrimental effects on the form. 
Frederick J. Ryerson and Bartley B. Ebbinghaus, "Pyrochlore-rich Titanate Ceramics for the Immobilization of Plutonium: Redox Effects on Phase Equilibria in Cerium- and Thoriumsubstituted Analogs," 69 pp., UCRL-ID-139092, Lawrence Livermore National Laboratory, Livermore, CA, June 2000 (000710).

This report describes a study of the effect of oxygen fugacity on the phase equilibria of the baseline ceramic for plutonium immobilization.

Three compositions representing plutonium-free analogs of the baseline Ca-Ti-Gd-Hf-U-Pu oxide ceramic were equilibrated at 1 atmosphere pressure and $1350^{\circ} \mathrm{C}$ over a range of oxygen fugacities between that of air and that equivalent to the iron-wustite buffer. A Ce replaced $\mathrm{Pu}$ on a mole-per-mole basis with $\mathrm{Ce}$; a thorium analog replaced $\mathrm{Pu}$ with $\mathrm{Th}$. A third material had 10 wt. $\% \mathrm{Al}_{2} \mathrm{O}_{3}$ added to the cerium analog to encourage the formation of a $\mathrm{Hf}$-analog of zirconolite, $\mathrm{CaHfTi}_{2} \mathrm{O}_{7}$. The predominant phase produced in each formulation under all conditions was pyrochlore, $\mathrm{X}_{2} \mathrm{Ti}_{2} \mathrm{O}_{7}$, where the $\mathrm{X}$ site was filled by $\mathrm{Ca}$, the lanthanides, $\mathrm{Hf}, \mathrm{U}$ and $\mathrm{Pu}$. Other lanthanide- and uranium-bearing phases encountered included brannerite $\left(\mathrm{UTi}_{2} \mathrm{O}_{6}\right)$, hafnolite $\left(\mathrm{CaHfTi}_{2} \mathrm{O}_{7}\right)$, perovskite $\left(\mathrm{CaTiO}_{3}\right)$ and a calcium-lanthanide aluminotitanate with nominal stoichiometry $(\mathrm{Ca}, \mathrm{Ln}) \mathrm{Ti}_{2} \mathrm{Al}_{9} \mathrm{O}_{19}$, where $\mathrm{Ln}$ is a lanthanide. The mineral chemistry and phase assemblage of these ceramics showed systematic variations with changes in the oxygen fugacity. These variations seemed to be largely due to the reduction of uranium under more reducing conditions. The main variation was an increase in the uranium concentrations of pyrochlore and brannerite, which was accommodated by variations in modal abundance. In spite of variations in oxygen fugacity over more than 10 orders of magnitude, all of the phases observed had previously been identified in titanate-based high-level radioactive waste ceramics, and this demonstrates the flexibility of these ceramics to variations in processing parameters. The desired phase assemblage, pyrochlore + brannerite + rutile, is favored by more oxidizing conditions. Reduction leads to the formation of perovskite and the calcium-lanthanide aluminotitanate. Both these phases incorporated lanthanides in these analog materials, and would be likely to incorporate plutonium in the actual immobilization form. Since it is planned to sinter the immobilization form in air, these unintended phases are not expected to form during actual ceramic production. 
Frederick J. Ryerson, Bartley B. Ebbinghaus, Oscar H. Krikorian, and Richard A. Van Konynenburg, "Saturation of Impurity-rich Phases in a Cerium-substituted Pyrochlore-rich Titanate Ceramic: Part 1. Experimental Results," 90 pp, UCRL-ID-139093 part 1, Lawrence Livermore National Laboratory, Livermore, CA, June 2000 (000709).

This report describes a study to determine the accessory phases produced by the addition of excess impurities in the baseline phases, and to determine the partitioning of the impurities among the phases present. Cerium was used as a surrogate for plutonium. The impurities were added separately (or in a few cases, two or three together). Sufficient impurity material was added in most cases to form an accessory phase with the impurity as a major constituent. This excess of impurity was added in order to quantify the solubility limits of the impurities in the major phases and to identify the accessory phases that would form. It was also important to determine to what degree the plutonium surrogate and the neutron absorber elements would enter these accessory phases.

The samples were fabricated from starting materials that consisted of hydroxides, nitrates, hydrated nitrates, carbonates, ammoniates and oxides. The starting materials were ground and mixed by hand under ethanol in an alumina mortar and pestle. Pressed pellets were sintered in air in excess of 24 hours at temperatures of 1300,1350 and $1400^{\circ} \mathrm{C}$. Quantitative characterization was performed by electron microprobe.

Pyrochlore was found in the product in all cases except when Si or P were present in excess. In these two cases, brannerite and rutile were still present, along with a Si-rich glass phase or a $\mathrm{P}$ rich glass and whitlockite $\left(\mathrm{Ca}_{3}\left(\mathrm{PO}_{4}\right)_{2}\right)$.

It was found that significant amounts of most of the impurities could be incorporated in one or more of the baseline phases. Much of the $\mathrm{Cu}$ and $\mathrm{Zn}$ and all of the $\mathrm{F}$ appeared to have volatilized during sintering.

Examination of the composition of the accessory phases showed that in the few cases where the $\mathrm{Pu}$ surrogate $(\mathrm{Ce})$ was incorporated in significant amounts, it was accompanied by significant amounts of the neutron absorber elements, Gd and/or Hf. An exception was "galonite," (a gallium-rich version of zirconolite), but this is not expected to actually form in the production ceramic because of the low expected concentration of gallium and the expected presence of aluminum, which favors the formation of pseudobrookite and hafnolite. 


\section{WSRC Reports}

The following three reports provided by WSRC have been summarized:

- Impurity Tolerance Tests Using Surrogates for Pu and U

- Impurity Tolerance and Thermal Effects Tests

- Volatile Impurities in the Ceramic Form for the Plutonium Immobilization Project (PIP) 
H.L. Halsey and J.L. Hood, "Impurity Tolerance Tests Using Surrogates for Pu and U," SRTMTS-97-3017, 60 pp., August 15, 1997 (000499).

This report describes work directed toward determining the effects of impurities on the phase composition of the pyrochlore-based ceramic. In this work Th was used as a surrogate for $U$, and Ce was used as a surrogate for Pu. Samples were prepared by the oxide process, followed by cold pressing and sintering at $1350^{\circ} \mathrm{C}$ for four hours in argon. Analysis was performed by $\mathrm{x}$-ray diffraction and by scanning electron microscopy with energy-dispersive $\mathrm{x}$-ray analysis.

Using the baseline composition, the major phase formed was pyrochlore. Also formed were minor amounts of perovskite and rutile, and trace amounts of zirconolite and brannerite.

Tests with various impurity mixes produced these same phases, in addition to an amorphous silicate phase, and an orthorhombic phase $\mathrm{Ca}_{3} \mathrm{X}_{6} \mathrm{TiO}_{9}$, where $\mathrm{X}$ is ( $\mathrm{Hf}, \mathrm{Al}, \mathrm{Th}, \mathrm{Gd}$, or $\mathrm{Ce}$ ). 
J.W. Congdon, "Impurity Tolerance and Thermal Effects Tests," SRT-MTS-97-3015, 89 pp., July 18, 1997 (000503).

This report describes testing that was performed to determine the effects of feed material impurities on the pyrochlore-based ceramic for plutonium immobilization, and to determine the effects of the thermal cycling that would occur during the pouring of molten glass around the cans containing the ceramic in the Defense Waste Processing Facility.

Small-scale pellets containing cerium oxide as a surrogate for plutonium oxide were fabricated at Clemson University. The pellets also contained $20 \mathrm{wt}$. $\%$ uranium oxide (natural uranium). SRTC analyzed the pellets using $x$-ray diffraction and scanning electron microscopy with energy-dispersive $x$-ray spectrometry. Pellets of each composition were thermally cycled to simulate the DWPF glass pouring and cooling conditions and were examined by XRD to look for changes in the crystal structure.

It was found that the baseline composition produced the desired pyrochlore-based crystal structure. Brannerite and rutile were also found to be present in the baseline samples. A few undissolved particles of urania were isolated within the brannerite. As the concentration of impurities was increased, the abundance of brannerite decreased. At relatively high impurity concentrations, the impurities formed a phase which was apparently amorphous. The EDS analyses indicated that traces of cerium (which was a surrogate for plutonium), uranium, and the neutron absorbers (hafnium and gadolinium) were contained in portions of the amorphous phase, although the electron beam may have excited crystalline phases below the amorphous regions, since some impurity regions showed no indication of the actinides or the neutron absorber elements. Platelet-shaped crystals, identified as monoclinic zirconolite, formed within the larger impurity regions and may have absorbed most of the actinides and neutron absorbers from the impurity regions. The abundance of zirconolite was found to increase as the impurity concentrations in the starting mix were increased.

Measurements of the bulk densities of the samples showed that the density decreased in proportion to the total amount of impurities present.

The crystal structures of the ceramics, as indicated by XRD, were unchanged by the thermal cycling. 
A.D. Cozzi, J.C. Marra, J.M. Pareizs, A.R. Jurgensen, D.M. Missimer, K.G. Brown, and T.B. Edwards, "Volatile Impurities in the Ceramic Form for the Plutonium Immobilization Project (PIP)," WSRC-TR-99-00479, 48 pp., January 2000 (000594).

This report describes tests directed at determining the maximum levels of 15 volatile impurities that can be accommodated in the pyrochlore-based ceramic without significantly affecting the porosity or the phase assemblage. The volatiles studied were classified in three groups: oxides (e.g. $\mathrm{PbO}, \mathrm{WO}_{3}$ and $\mathrm{ZnO}$ ), chlorides (e.g. $\mathrm{NaCl}, \mathrm{KCl}$, and $\mathrm{CaCl}_{2}$ ), and fluorides (e.g. $\mathrm{CaF}_{2}$ and $\mathrm{MgF}_{2}$ ).

The impurity studies were first performed with cerium as a surrogate for both plutonium and uranium. These tests were later repeated with cerium substituted only for plutonium. A subset of the tests was performed with thorium as the plutonium surrogate. A selected set of the sample compositions was repeated using actual plutonium to verify the results observed using surrogates. The pellets were prepared by the oxide process, were cold pressed and were sintered at $1350^{\circ} \mathrm{C}$ for four hours in air.

Single additions of impurities caused formation of small amounts of phases that were not present in the impurity-free reference pellets. In comparison to single impurity additions, simultaneous additions of multiple impurities reduced the number of ancillary phases as well as the relative amounts of these phases. The total amount of impurities added during the simultaneous additions ( 0.6 moles of impurity per mole of plutonium) was equivalent to the amount of each of the singularly added impurities. Densification, as measured by apparent porosity, was significantly affected by eleven of the fifteen impurities. Sodium chloride produced the greatest reduction in density. Additions of $\mathrm{MgCl}_{2}, \mathrm{ZnCl}_{2}, \mathrm{MgF}_{2}$, and $\mathrm{CaF}_{2}$ had no discernible effect on the density of the form. Several two-factor interactions appeared to be significant in either increasing or decreasing the apparent porosity of the ceramic, but the data were not sufficient for a definitive assessment of the importance of the interactions. 